\title{
Functional health literacy in Spanish-speaking Latinas seeking breast cancer screening through the National Breast and Cervical Cancer Screening Program
}

\author{
Samantha Garbers' \\ Karen Schmitt ${ }^{2}$ \\ Anne Marie Rappa ${ }^{2}$ \\ Mary Ann Chiasson' \\ 'Public Health Solutions, New York, \\ NY, USA; ${ }^{2}$ Columbia University Breast \\ Cancer Screening Program, New York, \\ NY, USA
}

\begin{abstract}
Background: This analysis examines the association between functional health literacy and follow-up after mammography among women receiving breast cancer screening at a National Breast and Cervical Cancer Early Detection Program site in New York City that provides universal bilingual case management.
\end{abstract}

Methods: A total of 707 Latinas who spoke Spanish as their primary language completed a survey of health and demographic characteristics and the Test of Functional Health Literacy in Spanish (TOFHLA-S). Survey results were matched with clinical outcome data.

Results: Among the survey participants, 98\% were foreign-born and 99\% had no health insurance. While the study found significant differences in access to health information and past screening behavior, women without adequate health literacy in Spanish were no less likely to receive clinical resolution of abnormal mammograms within 60 days $(81.8 \%$ overall; $\mathrm{n}=110)$ or to return for a repeat mammogram within 18 months $(57.2 \%$ overall; $n=697)$. In fact, among those referred for a Pap test $(n=310)$, women without adequate health literacy were more likely to receive a Pap test within 60 days of their mammogram than those with adequate health literacy ( $82 \%$ compared to $71 \%$, OR: $1.83,95 \%$ CI: 1.04-3.22).

Discussion: The lack of significantly lower follow-up outcomes among women with inadequate and marginal functional health literacy in this population of primary Spanish-speaking Latinas suggests that, once women have accessed screening services, programmatic approaches may exist to mitigate barriers to follow-up and to ensure optimal cancer screening outcomes for women of all literacy levels.

Keywords: health literacy, mammography, Latinas, case management, cancer screening

\section{Background}

While disparities in breast cancer screening rates have narrowed in the US, screening rates continue to be lower among Latinas than among non-Hispanic white women. ${ }^{1}$ Recent research has found that lower socioeconomic status, independent of race and ethnicity, is associated with disparities in screening use $\mathrm{e}^{2-5}$ as well as mortality and survival rates. ${ }^{6,7}$ The most recent National Assessment of Adult Literacy revealed that some population subgroups, particularly Hispanic ${ }^{a}$ men and women and adults age 65 and older, were significantly more likely to score in the "below basic" category for prose, document and quantitative literacy. ${ }^{8}$ Recent research has examined the association between health literacy and health outcomes and health care utilization, ${ }^{9,10}$ with several reports finding a strong association between

${ }^{\text {an }}$ this manuscript, the term Latino/a is used, except when referring to reports published by others. In these cases, the term used in the original document is used. 
health literacy and breast and cervical cancer screening behavior among Latinas. ${ }^{11,12}$

In addition to the barriers to obtaining breast cancer screening, there are barriers to follow-up after screening, with low income women and Latinas less likely to obtain appropriate follow-up after abnormal mammograms. ${ }^{13-15}$ The literacy burden of follow-up after mammography is high, ${ }^{16}$ with numerous potential failures during the process of care. ${ }^{17-19}$

The National Breast and Cervical Cancer Early Detection Program (NBCCEDP), funded by the Centers for Disease Control and Prevention (CDC), was established to provide screening and diagnostic services for uninsured, low income women (at or below $250 \%$ of the federal poverty level). Since 1991, NBCCEDP-funded programs have served more than 3.2 million women. The proportion of American adults who are at risk of inadequate health literacy steadily increasing, ${ }^{20}$ and more than one-third of the women receiving mammograms through NBCCEDP programs were of Hispanic ethnicity. ${ }^{21}$ Barriers and programmatic solutions to providing appropriate follow-up after breast cancer screening for low income Latinas, specifically those with low functional health literacy, are therefore of particular concern to NBCCEDP providers. Research was undertaken to examine the association between functional health literacy in Spanish and follow-up after mammography in a population of primary Spanish-speaking Latinas seeking cancer screening services at an NBCCEDP site that offers routine bilingual case management integrated into care.

\section{Methods}

\section{Study population}

Women seeking breast and/or cervical cancer screening services at two NBCCEDP sites were recruited for the study. On approximately three recruitment days each week (including one Saturday each month), from October 2005 to September 2006, all women who were awaiting screening appointments at the sites were approached in the waiting room. Reflecting the demographic profile of the patients served by the sites at the time the protocol was developed, the study included only women who self-identified as Hispanic or Latina and/or Black or African-American. Only women who met NBCCEDP eligibility criteria - uninsured or underinsured, aged 40 or over or younger if at increased risk of breast cancer, and not screened in the last year - were eligible for the study. After screening for the above eligibility criteria, the interviewer described the study, provided a flyer, and read aloud the informed consent statement. Interviewers were bilingual (Spanish/English), and conducted the entirety of the interviews in either Spanish or English, as requested by the participant. Participation in the study included written informed consent, administration of a 31-item survey on health behaviors, and administration of the Test of Functional Health Literacy in Adults (TOFHLA or TOFHLA-S). ${ }^{22,23}$ The informed consent included permission to release "information from your health record about: what kind of cancer screening tests you had; what the results were; and any other tests related to the cancer screening that you needed within two years after your first screening".

All materials, including the consent form and survey, were read aloud to all participants. Materials were developed using simple words and short sentences. The informed consent scored at a 7 th grade reading level (using both SMOG [Simple Measure of Gobbledygook] ${ }^{24}$ and FleschKincaid $^{25}$ scales), with reading grade level inflated by the inclusion of the institutions' (polysyllabic) names. The study was reviewed and approved by the Institutional Review Boards both at Public Health Solutions and at Columbia University.

This analysis includes only Spanish-speaking Latinas recruited at the larger of the two participating sites, located in Washington Heights, New York City. At this site, 1,426 women were approached to participate in the study; of these, $623 \mathrm{did}$ not meet the eligibility criteria listed above, 38 were eligible but refused to participate ( $4.7 \%$ of those eligible), and 765 agreed to participate. Of these 765 participants, 24 were African American, 26 Latinas completed the survey but refused participation in the TOFHLA, ${ }^{\mathrm{b}}$ and eight completed the survey in English. To ensure the comparability of participants, these 58 patients were excluded from the dataset, leaving a sample size of 707. Figure 1 summarizes the inclusion and exclusion of participants as well as the screening services and general outcome for participants included in the analysis.

\section{Survey instrument}

The survey was developed in English, translated to Spanish, and back-translated for review. The translation to Spanish was reviewed by a second team of translators at the screening site. Survey items included demographic information (employment, nationality, acculturation, education, marital status); internet use and access; general health status (height and weight, chronic health conditions); access to health care and insurance continuity; use of health care and communication with provider, including locus of control measures; and

${ }^{b}$ Latinas who did not complete the TOFHLA-S differed significantly from those who did complete the TOFHLA-S on only one of the survey items. Women who did not complete the TOFHLA were significantly more likely to report that they had not followed a provider's instructions in the last year (Chi square $=12.3, \mathrm{p}=0.002$ ). 


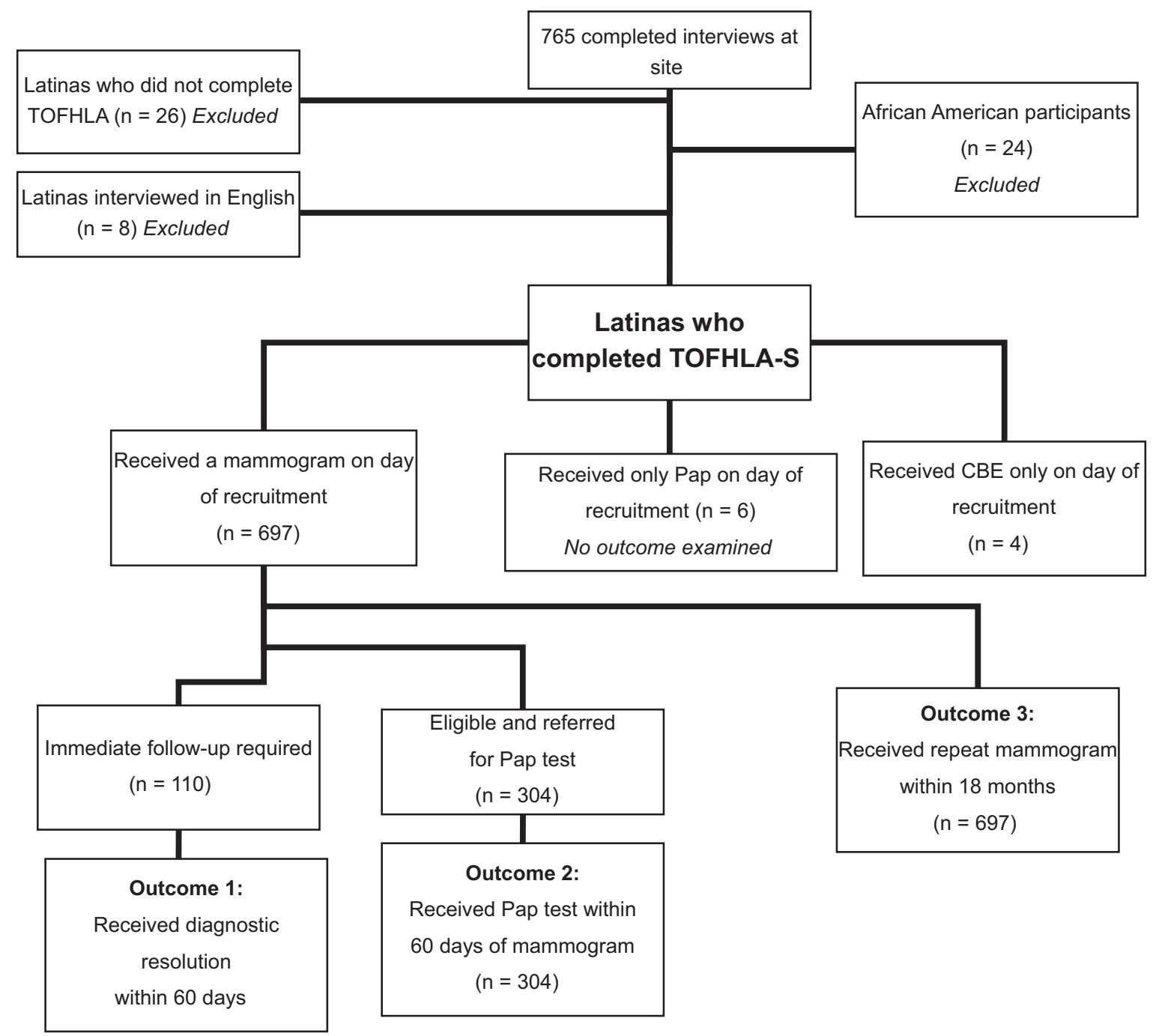

Figure I Summary of participants, services, and outcomes among Spanish-speaking Latinas seeking breast and cervical cancer screening $(\mathrm{N}=707)$.

cancer screening attitudes and behavior. The survey was developed for the purposes of this study. Whenever possible, survey questions made use of existing pretested items, including the Behavioral Risk Factor Surveillance System; previous surveys on breast cancer screening knowledge, attitudes, and behavior, ${ }^{26,27}$ surveys on health care quality; ${ }^{28}$ and the Short Acculturation Scale for Hispanics. ${ }^{29}$ All data were analyzed without patient identifiers. Survey participants were assigned a sequential numerical identification number that was linked to a different sequential numerical identification number related to their screening appointment. Using the linkage of these two identification numbers, the following data were exported from the electronic screening outcome database: mammogram results (BIRAD), clinical breast exam (CBE) findings, pelvic exam findings, Pap test results, recommended date of next exams, clinical follow-up dates and procedures, and treatment status (including lost-to-follow-up and refused).
Participants completed the TOFHLA-S, a screening instrument in Spanish that has been used in several settings to identify patients with low functional health literacy. The English version of the TOFHLA was tested by the developers for concurrent validity with other standardized literacy tests, but because there are no Spanish versions of the other standardized tests (Rapid Estimate of Adult Literacy in Medicine [REALM-R], Wide Range Achievement Test-Revised [WRAT-R]), ${ }^{30}$ concurrent validity with TOFHLA-S has not been measured. The TOFHLA-S includes both reading comprehension (employing a modified Cloze procedure) and numeracy sections. The results of the test yield a score from $0-100$ that includes equal contributions from each section. The test takes up to 22 minutes to administer. The TOFHLA-S score is categorized into three levels. Those with inadequate functional health literacy (TOFHLA score 0-59) are unable to read and interpret health texts. 
Those with marginal functional health literacy (TOFHLA score 60-74) have difficulty reading and interpreting health texts, while those with adequate functional health literacy (75-100) can read and interpret most health texts.

\section{Clinical services and case management}

A centralized case management format was part of routine clinical care at the participating screening site for all patients seeking screening services. Case management services were provided by bilingual (English/Spanish) staff. All communication of positive findings were provided using verbal and in lay language. Positive diagnostic results were immediately communicated by the radiologist to the case manager prior to the patient leaving the department. In communicating results, the case manger spoke with the patient, ensured that she understood the need for further diagnostic work-up, and made the appropriate appointment. The case manager offered to accompany the patient to any future appointments.

\section{Outcomes}

Clinical outcomes data were exported from the centralized patient care database using a sequential study ID (without personally identifying data). In this paper, three dichotomous outcomes were examined as indicated in Figure 1.

\section{Outcome I}

Among women who had an abnormal mammogram $(n=110)$, analyses examined whether they received diagnostic resolution after abnormal mammogram within 60 days (an outcome designated by NBCCEDP-reporting requirements).

\section{Outcome 2}

Second, among women who were referred for a Pap test $(\mathrm{n}=310),{ }^{\mathrm{c}}$ analyses examined whether they received one within 60 days of having the mammogram.

\section{Outcome 3}

Finally, return for a repeat mammogram within 18 months was examined among the women who had a mammogram on the day of survey completion $(n=697)$.

\section{Data analysis}

Data analysis was performed using SPSS statistical software version 14.0 (SPSS, Inc., Chicago, IL, USA). Statistical differences in the frequencies of demographic and health care characteristics

${ }^{\mathrm{c}}$ More than half of the women who received a mammogram were not referred to receive a Pap test through the program: $24 \%$ had had a Pap within the last year, $16 \%$ had no cervix intact, $8.2 \%$ refused the referral, and $6.8 \%$ had had three consecutive normal Pap tests. by functional health literacy groups were assessed by chi-square tests or Fisher exact tests for categorical variables and analysis of variance for continuous variables. Bivariate odds ratios and $95 \%$ confidence intervals were calculated for all survey items and the outcomes listed above by TOFHLA-S score group (inadequate, marginal, adequate). For the outcomes expressed as continuous variables, analysis of variance was used to examine differences by TOFHLA-S score group. The same analyses were repeated dichotomizing the TOFHLA-S score group (adequate; marginal and inadequate).$^{31}$

\section{Results}

Table 1 presents sociodemographic and health care information for the women in the sample $(\mathrm{N}=707)$. The average age of participants was $50.8(\mathrm{SD}=7.8)$. Almost all of the women (98\%) were foreign-born, with most born in the Dominican Republic (67\%) or South America (18\%). Nearly one-third had had elementary school education or less. Most of the women did not work for pay outside the home and were not currently married or living as married. Because of the eligibility criteria for screening through the NBCCEDP program, almost all (99\%) participants had no health insurance, and more than half did not have a regular source of care for their own general health. Program guidelines restrict services to uninsured and underinsured women at or below $250 \%$ of federal poverty. Scores on the TOFHLA-S were mixed: $24 \%$ had inadequate health literacy in Spanish, 14\% marginal, and 62\% adequate. One-tenth of the sample $(n=67)$ was unable to read any words (TOFHLA-S score of 0 ). Significant differences were found by functional health literacy level on all of the sociodemographic and health care variables studied, with the exception of having a visit to a health care provider in the last year.

Because this analysis included only the participants at the screening site who preferred to complete the survey in Spanish, levels of acculturation were low, and differed significantly by functional health literacy level. Less than $4 \%$ of the sample was born in the US or moved to the US before age 12. More than three-fourths reported that they read and spoke only Spanish. ${ }^{\mathrm{d}}$ Seventy-one percent of those with inadequate health literacy, $53 \%$ with marginal, and $37 \%$ with adequate health literacy reported that the television programs they usually watch are only in Spanish (Chi square test $=64.9, \mathrm{p}<0.001$ ).

A full $12 \%$ responded that there was a time in the last 12 months when they did not follow a health care provider's advice, or treatment plan, get a recommended test or see a

dQuestion wording, from Short Acculturation Scale for Hispanics: "In general, what language do you read and speak?" 
Table I Demographic and health care characteristics among women interviewed in Spanish, by functional health literacy level in Spanish $(\mathrm{N}=707)$

\begin{tabular}{|c|c|c|c|c|}
\hline \multirow[b]{2}{*}{ Characteristic } & \multirow[b]{2}{*}{$\begin{array}{l}\text { All women } \\
(\mathbf{N}=707), \text { No. (\%) }\end{array}$} & \multicolumn{3}{|c|}{ Health Literacy Level in Spanish (TOFHLA-S) } \\
\hline & & $\begin{array}{l}\text { Inadequate } \\
(n=I 70), \text { No. (\%) }\end{array}$ & $\begin{array}{l}\text { Marginal } \\
(n=I 00), \text { No. }(\%)\end{array}$ & $\begin{array}{l}\text { Adequate } \\
(n=437), \text { No. (\%) }\end{array}$ \\
\hline Age (years, mean) ${ }^{\dagger}(p<0.00 I)$ & 51 & 54 & 52 & 49 \\
\hline \multicolumn{5}{|l|}{ Language spoken in general $\left.\right|^{\mathrm{b} * * *}(\mathbf{p}<0.00 \mathrm{I})$} \\
\hline Spanish only & $538(76.1)$ & $156(91.8)$ & $79(79.0)$ & $303(69.3)$ \\
\hline Spanish more & $102(14.4)$ & $9(5.3)$ & $17(17.0)$ & $76(17.4)$ \\
\hline Both equal & $67(9.5)$ & $5(2.9)$ & $4(4.0)$ & $58(\mid 3.3)$ \\
\hline \multicolumn{5}{|l|}{ Birthplace $^{* * *}(\mathbf{p}<0.00 \mathrm{I})$} \\
\hline Dominican Republic & $476(67.3)$ & $135(79.4)$ & $78(78.0)$ & $263(60.2)$ \\
\hline South America & $130(18.4)$ & $15(8.8)$ & II (II.0) & $104(23.8)$ \\
\hline Central America & $37(5.2)$ & $5(2.9)$ & $6(6.0)$ & $26(5.9)$ \\
\hline Mexico & $34(4.8)$ & $10(5.9)$ & $3(3.0)$ & $21(4.8)$ \\
\hline Puerto Rico & II (I.6) & $2(1.2)$ & $2(2.0)$ & $9(2.1)$ \\
\hline Other (Cuba, Spain) & $7(1.0)$ & $2(1.2)$ & $2(2.0)$ & $3(0.7)$ \\
\hline US (not Puerto Rico) & $12(1.7)$ & $\mathrm{I}(0.6)$ & - & II (2.5) \\
\hline \multicolumn{5}{|l|}{ Proportion of life in the US** $(p=0.005)$} \\
\hline $75 \%-100 \%$ & $29(4.2)$ & $5(3.0)$ & $3(3.0)$ & $21(4.9 \%)$ \\
\hline $50 \%-74 \%$ & $154(22.0)$ & $29(17.1)$ & $18(18.2)$ & $107(24.8)$ \\
\hline $25 \%-49 \%$ & $219(31.2)$ & $43(25.3)$ & $43(43.4)$ & $133(30.8)$ \\
\hline Less than $25 \%$ & $299(42.7)$ & $93(54.7)$ & $35(35.4)$ & I7I (39.6) \\
\hline \multicolumn{5}{|l|}{ Employment status** $(p=0.001)$} \\
\hline Homemaker & $288(40.7)$ & $93(54.7)$ & $43(43.0)$ & $152(34.8)$ \\
\hline Full time or more, for pay & $121(17.1)$ & $13(7.6)$ & $22(22.0)$ & $87(19.9)$ \\
\hline Part time, for pay & $172(24.3)$ & $34(20.0)$ & $23(23.0)$ & $115(26.3)$ \\
\hline Retired/unable to work/unemployed & $96(13.6)$ & $25(14.7)$ & $10(10.0)$ & $61(14.0)$ \\
\hline Self-employed & $29(4.1)$ & $5(2.9)$ & $2(2.0)$ & $22(5.0)$ \\
\hline \multicolumn{5}{|l|}{ Educational attainment ${ }^{* * *}(\mathrm{p}<0.00 \mathrm{I})$} \\
\hline Elementary school or less & $226(32.0)$ & $124(73.4)$ & $30(30.0)$ & $72(16.5)$ \\
\hline Some high school & $113(16.0)$ & $21(12.4)$ & $22(22.0)$ & $70(16.0)$ \\
\hline High school graduate or GED & $164(23.2)$ & $14(8.3)$ & $25(25.0)$ & $125(28.6)$ \\
\hline Some college or more & $203(28.7)$ & $10(6.0)$ & $23(23.0)$ & $170(38.9)$ \\
\hline \multicolumn{5}{|l|}{ Marital status $(p=0.029) *$} \\
\hline Married or living as married & $281(39.7)$ & $56(32.9)$ & $33(33.0)$ & $192(43.9)$ \\
\hline Never married & $79(11.2)$ & $19(11.2)$ & $9(9.0)$ & $5 \mathrm{I}(\mathrm{II} .7)$ \\
\hline Separated/divorced or widowed & $347(49.1)$ & $95(55.9)$ & $58(58.0)$ & $194(44.4)$ \\
\hline \multicolumn{5}{|l|}{ Health care } \\
\hline No source of health care* $(p=0.042)$ & $389(55.0)$ & $108(63.5)$ & $60(60.0)$ & $221(50.6)$ \\
\hline No visit to health care provider in last year (NS) & $176(25.3)$ & $39(23.6)$ & $17(17.2)$ & $120(27.7)$ \\
\hline \multicolumn{5}{|l|}{ Health conditions } \\
\hline $\begin{array}{l}\text { Any health condition (high blood pressure, } \\
\text { high cholesterol, asthma, cancer } \\
\text { and/or diabetes)* }(\mathrm{p}=0.043)\end{array}$ & $392(55.4)$ & $106(62.4)$ & $47(47.0)$ & $239(54.7)$ \\
\hline Overweight or obese $(\mathrm{BMI}>25)^{*}(\mathrm{p}=0.04)$ & $439(64.9)$ & II5 (73.2) & $59(60.2)$ & $265(62.9)$ \\
\hline
\end{tabular}

Notes: ${ }^{\mathrm{Q}} \mathrm{Questions} \mathrm{used} \mathrm{from} \mathrm{the} \mathrm{Short} \mathrm{Acculturation} \mathrm{Scale} \mathrm{for} \mathrm{Hispanics;}{ }^{29}{ }^{\dagger} \mathrm{p}<0.05$ by one-way ANOVA for the association between literacy level and the characteristic; Chi square test for the association between literacy level and the characteristic; ${ }^{*} \mathrm{p}<0.05$; ${ }^{* *} \mathrm{p}<0.0 \mathrm{I}$; *** $\mathrm{p}<0.00 \mathrm{I}$.

Abbreviations: BMI, body mass index; GED, General Education Development; NS, not significant. 
referred doctor for any reason, the most common reason being $\operatorname{cost}(50 \%$ of those who indicated they did not follow a provider's advice) or that the instructions were too difficult ( $25 \%$ of those who reported not following a provider's advice). Eighteen percent reported that, at their last visit, they had questions about their care or treatment that they wanted to discuss, but did not. More than 7\% reported that they understood only "some" or "only a little" of what the health care provider said at the last visit, with women without adequate health literacy significantly more likely (odds ratio $[\mathrm{OR}]=2.08,95 \%$ confidence interval [CI]: 1.17-3.69) to report lower comprehension. Patients with inadequate or marginal health literacy were also significantly more likely to agree with statements associated with external locus of control, as shown in Figure 2, with women without adequate functional health literacy almost four times more likely to agree with the statement "I think staying healthy is a matter of luck more than anything else" (OR: 3.8, 95\% CI: 2.8-5.3).

Access to the internet, a source of health information for the general population in the US, was low, and differed significantly by functional health literacy level: $5 \%$ of those with inadequate health literacy, $12 \%$ of those with marginal health literacy, and 35\% with adequate health literacy had access to the internet in any location (Chi square test $=68.9$, $\mathrm{p}<0.0001)$. Less than $3 \%$ of participants without adequate health literacy reported ever using the internet to get health or medical information.

Women without adequate health literacy were significantly less likely to report breast cancer screening histories consistent with clinical recommendations. Among the women age 40 and over $(n=702)$, those who had adequate functional health literacy had 1.5 the odds of reporting having had their first mammogram at or before age 40 (OR $=1.54,95 \%$ CI: 1.13-2.09); among women age 50 and over $(n=353)$, women with adequate functional health literacy had 3 times the odds of having had a first mammogram at or before age 50 (OR $=3.28,95 \%$ CI: 1.99-5.42). While the CDC recommends initiation of cervical cancer screening at age 21 (or earlier, within three years of initiating sexual activity) ${ }^{32}$, among women with inadequate health literacy, $23.5 \%$ had had their first Pap test at age 21 or earlier, compared to $15.8 \%$ of those with marginal health literacy, and $26.1 \%$ of those with adequate health literacy (Chi square test $\mathrm{p}=0.105$ ). The study was reviewed and approved by the Institutional Review Boards both at Public Health Solutions (formerly Medical and Health Research Association of New York City, Inc. (MHRA)) and at Columbia University.

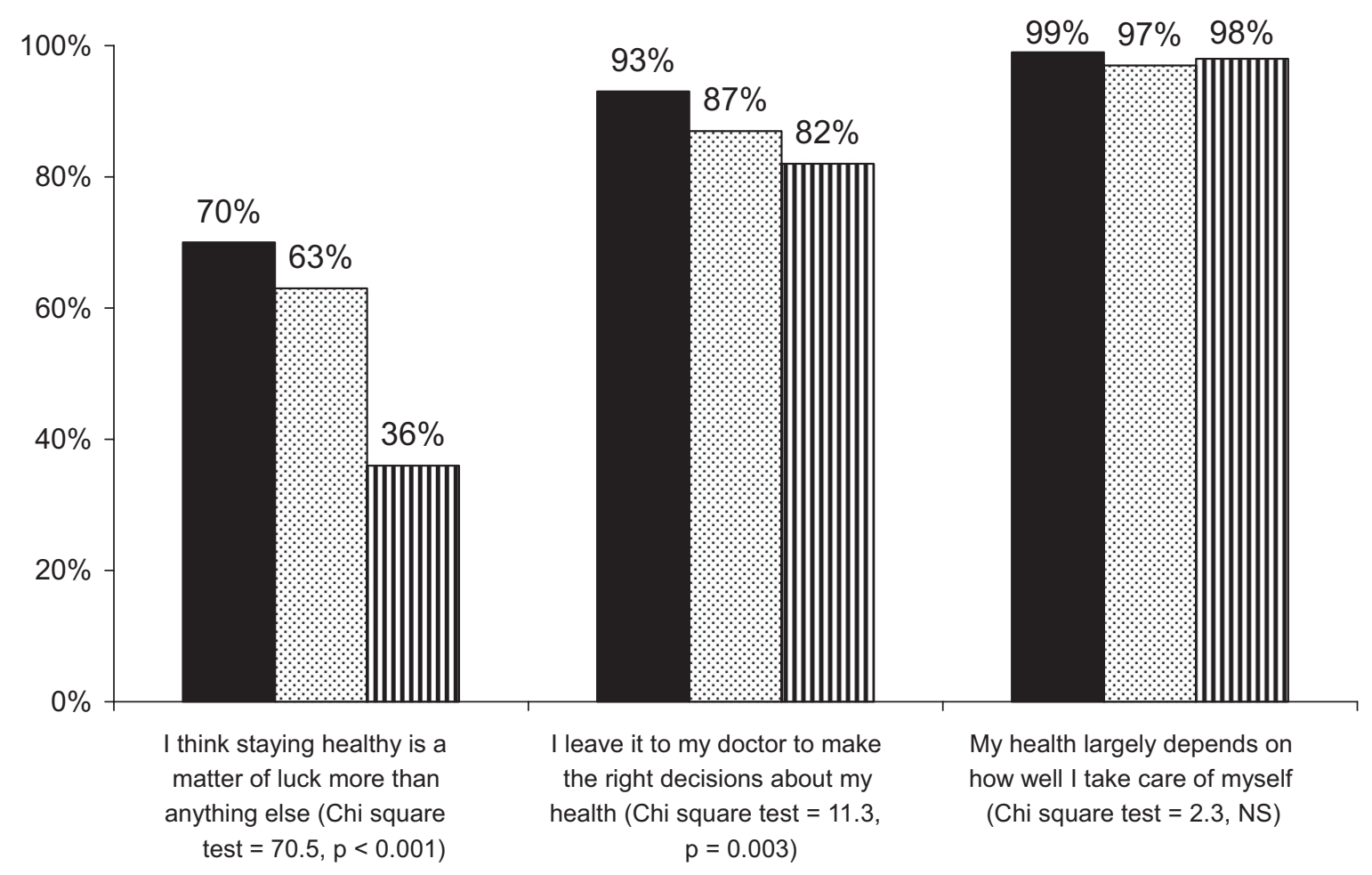

Inadequate $(n=170)$. Marginal $(n=100)$ mAdequate $(n=437)$

Figure 2 Proportion who responded "strongly agree" or "somewhat agree" to statements related to locus of control $(\mathrm{N}=707)$. 


\section{Outcome I: Follow-up after abnormal mammogram}

Women without adequate functional health literacy were no more or less likely than those with adequate health literacy to require immediate follow-up after their mammogram. Among the 110 women who did require immediate follow-up after their mammogram, no differences were found by literacy level in the proportion who had diagnostic resolution within 60 days $(82 \%$ of all patients, Chi square test $p=0.763$ ). A total of six patients refused follow-up or were lost to follow-up, four of whom had adequate health literacy and two who did not (Fisher's exact test $\mathrm{p}=0.621$ for one-sided test; $\mathrm{p}=1.000$ for twosided test). No significant differences in this outcome were found by age, birthplace, years in the US, or educational attainment.

\section{Outcome 2: Receipt of Pap test after mammogram}

A total of 310 women received both a mammogram and a referral for Pap test through the program. Among these women, only six did not receive the Pap test, with no differences by literacy level (Fisher's exact test $p=0.621$ for one-sided test; $p=1.000$ for two-sided test). Actually, women without adequate health literacy were more likely to receive a Pap test within 60 days of their mammogram than those with adequate health literacy ( $82 \%$ compared to $71 \%$, $\mathrm{OR}=1.83,95 \% \mathrm{CI}: 1.04-3.22)$. After running an adjusted logistic regression model examining this outcome by literacy group, controlling for enrollment on Saturdays (when Pap tests and mammograms were available on the same day), similar results were found ( $\mathrm{OR}=2.27,95 \% \mathrm{CI}$ : $1.13-4.60)$. As with the previous outcome, no significant differences in the outcome were found by age, birthplace, years in the US, or educational attainment.

\section{Outcome 3: Return for annual mammogram within 18 months}

Among the 697 women who received a mammogram on the date of survey administration, $56.9 \%$ returned for a repeat mammogram within 18 months (a cutoff designated by NBCCEDP reporting guidelines). As with the other two outcomes, as shown in Table 2, no significant differences were found by functional health literacy level in Spanish (Chi square test $p=0.75$ ). Women who returned for a repeat mammogram within 18 months were slightly older than those who did not (mean ages 51.7 and 49.7, respectively; ANOVA $p=0.001$ ). As with the previous outcome, no significant differences in the outcome were found by birthplace, years in the US, or educational attainment.

\section{Discussion}

The current study confirms previous studies showing that women with low functional health literacy have been shown to be significantly less likely to initiate breast cancer screening consistent with national screening guidelines. ${ }^{10,11}$ This study expands on the existing literature to look at women of varying functional health literacy levels who have already entered a screening program, despite the barriers, with a particular emphasis on Spanish-speaking Latinas. In the screening program studied, $38 \%$ of primary Spanish-speaking participants had inadequate or marginal health literacy in Spanish, with a full 10\% of the women studied not able to read any words in Spanish (TOFHLA-S score of 0 ). The women studied in this analysis are facing competing health concerns and lack of continuity of care or health insurance outside the screening setting, challenges that were significantly more prevalent among those with lower functional health literacy. Patients with inadequate health literacy were also significantly more likely to lack access to health information through the Internet, work-based

Table 2 Follow-up outcome measures by functional health literacy level in Spanish

\begin{tabular}{|c|c|c|c|c|c|}
\hline & \multirow[b]{2}{*}{$\begin{array}{l}\text { All women } \\
\mathrm{n}(\%)\end{array}$} & \multicolumn{3}{|c|}{$\begin{array}{l}\text { Functional Health Literacy Level in Spanish } \\
\text { (TOFHLA-S) }\end{array}$} & \multirow[b]{2}{*}{$\begin{array}{l}\text { Chi square } \\
\text { test (p-value) }\end{array}$} \\
\hline & & $\begin{array}{l}\text { Inadequate } \\
\text { n (\%) }\end{array}$ & $\begin{array}{l}\text { Marginal } \\
\text { n (\%) }\end{array}$ & $\begin{array}{l}\text { Adequate } \\
\mathrm{n}(\%)\end{array}$ & \\
\hline $\begin{array}{l}\text { Outcome I: Diagnostic resolution within } \\
60 \text { days for abnormal mammogram }(n=110)\end{array}$ & $90(81.8)$ & $20(83.3)$ & 14 (87.5) & $56(80.0)$ & $0.54(p=0.763)$ \\
\hline $\begin{array}{l}\text { Outcome 2: Received Pap test within } 60 \text { days } \\
\text { of mammogram }(n=310)\end{array}$ & $231(74.5)$ & 61 (84.7) & 31 (75.6) & $139(70.6)$ & $5.6(p=0.06 I)$ \\
\hline $\begin{array}{l}\text { Outcome 3: Return for repeat mammogram } \\
\text { within } 18 \text { months }(n=697)\end{array}$ & $399(57.2)$ & $92(55.1)$ & $55(56.1)$ & $252(58.3)$ & $0.58(p=0.75)$ \\
\hline
\end{tabular}


information, or a spouse. Nevertheless, our study included women who overcame these barriers, and were able to seek care. No significant differences were found by literacy level in the three follow-up outcomes studied in a setting in which bilingual case management was provided as part of routine clinical care.

This study had some limitations. Women with lower literacy skills may have been more likely to refuse participation because of the actual or perceived literacy burden of the study, resulting in an underestimate of the proportion of women with inadequate health literacy in the screening population. This study measured functional health literacy in Spanish, the primary language of participants in the analysis. While we did not measure participants' functional health literacy in English, an unknown proportion of the women we studied who were found to have adequate functional health literacy in Spanish would not have adequate functional health literacy in English, the primary language in which health care services and education are provided in the US. This analysis focused on Latina immigrant women in New York City whose primary language is Spanish. The findings presented here may not be generalizable to other ethnic populations, to women living in other areas, or to Latinas whose primary language is English. Reliability testing was not conducted on the survey instrument. Finally, the rates of follow-up at the clinical site were significantly higher than anticipated based on previously published research; ${ }^{33}$ as a result, the study may did not have adequate statistical power to detect the small differences in follow-up by literacy level.

In a clinical setting in which bilingual case management ${ }^{34,35}$ was standard of care, the finding that follow-up outcomes were similar regardless of functional health literacy level suggests that once women have accessed screening services, programmatic approaches may mitigate barriers to follow-up and ensure optimal cancer screening outcomes for women of all literacy levels. Interventions that address literacy-related barriers across the screening continuum - not only in promoting initiation of mammography screening but also adherence to recommendations for repeat screening, and follow-up of abnormal results - for low income women with low functional health literacy may be a key step in reducing persistent disparities in breast cancer outcomes. ${ }^{1,36,37}$

\section{Disclosure}

The authors report no conflicts of interest in this work.

\section{References}

1. Peek ME, Han JH. Disparities in screening mammography: Current status, interventions and implications. J Gen Int Med. 2004;19:184-194.

2. Rodriguez MA, Ward LM, Perez-Stable EJ. Breast and cervical cancer screening: Impact of health insurance status, ethnicity, and nativity of Latinas. Ann Fam Med. 2005;3(3):235-241.

3. Ward E, Jemal A, Cokkinides V, et al. Cancer disparities by race/ethnicity and socioeconomic status. CA Cancer J Clin. 2004;54:78-93.

4. Wells KJ, Roetzheim RG. Health disparities in receipt of screening mammography in Latinas: A critical review of recent literature. Cancer Control. 2007;14(4):369-379.

5. Smith-Bindman R, Miglioretti DL, Lurie N, et al. Does utilization of screening mammography explain racial and ethnic differences in breast cancer? Ann Intern Med. 2006;144:541-553.

6. Baquet CR, Commiskey P. Socioeconomic factors and breast carcinoma in multicultural women. Cancer. 2000;88(Suppl 5):1256-1264.

7. Harper S, Lynch J, Meersman SC, Breen N, David WW, Reichman MC. Trends in area-socioeconomic and race-ethnic disparities in breast cancer incidence, stage at diagnosis, screening, mortality, and survival among women ages 50 and over (1987-2005). Cancer Epi Biomarkers Prev. 2009;18(1):121-131.

8. Kutner M, Greenberg E, Jin Y, Paulsen C. The Health Literacy of America's Adults: Results From the 2003 National Assessment of Adult Literacy (NCES 2006-483). US Department of Education. Washington, DC: National Center for Education Statistics; 2006.

9. Nielsen-Bohlman L, Panzer AM, Kindig DA, Editors. Committee on Health Literacy. Health Literacy: A Prescription to End Confusion. Washington, DC: Institute of Medicine, 2004.

10. Berkman ND, DeWalt DA, Pignone MP, et al. Literacy and Health Outcomes. Summary, Evidence Report/Technology Assessment No. 87. AHRQ Publication No. 04-E007-1. Rockville, MD: Agency for Healthcare Research and Quality, 2004.

11. Guerra CE, Krumholz M, Shea J. Literacy and knowledge, attitudes and behavior about mammography in Latinas. $J$ Health Care Poor Underserved. 2005;16(1):152-166.

12. Garbers $\mathrm{S}$, Chiasson MA. Inadequate functional health literacy in Spanish as a barrier to cervical cancer screening among immigrant Latinas in New York City. Prev Chron Dis. 2004;1(4):A07.

13. Strzelczyk JJ, Dignan MB. Disparities in adherence to recommended follow-up on screening mammography: interaction of sociodemographic factors. Ethn Dis. 2002;12(1):77-86.

14. Kerner JF, Yedidia M, Padgett D, et al. Realizing the promise of breast cancer screening: clinical follow-up after abnormal screening among Black women. Prev Med. 2003;37:92-101.

15. McCarthy BD, Yood MU, Boohaker EA, Ward RE, Rebner M, Johnson CC. Inadequate follow-up of abnormal mammograms. Am J Prev Med. 1996;12(4):282-288.

16. Schwartz LM, Woloshin S, Black WC, Welch HG. The role of numeracy in understanding the benefit of screening mammography. Ann Intern Med. 1997;127(11):966-972.

17. Zapka JG, Taplin SH, Solberg LI, Manos MM. A framework for improving the quality of cancer care: the case for breast and cervical cancer screening. Cancer Epidemiol Biomarker Prev. 2003;12(1):4-13.

18. Davis TC, Williams MV, Marin E, Parker RM, Glass J. Health literacy and cancer communication. CA Cancer J Clin. 2002;52:134-149.

19. Angus J, Miller KL, Pulfer T, McKeever P. Studying delays in breast cancer diagnosis and treatment: Critical realism as a new foundation for inquiry. Oncol Nurs Forum. 2006;33(4):E62-E70.

20. Hobbs F, Stoops N. US Census Bureau, Census 2000 Special Reports, Series CENSR-4, Demographic Trends in the 20th Century. Washington, DC: US Government Printing Office; 2002.

21. Centers for Disease Control and Prevention (CDC). National Breast and Cervical Cancer Early Detection Program: About the Program. January 2009. Accessed on January 15, 2009. Available from http://www.cdc. gov/cancer/nbccedp/about.htm. 
22. Davis TC, Michielutte R, Askov EN, Williams MV, Weiss BD. Practical assessment of adult literacy in health care. Health Educ Behav. 1998;25(5):613-624.

23. Parker RM, Baker DW, Williams MV, Nurss JR. The Test of Functional Health Literacy in Adults: A new instrument for measuring patients' literacy skills. J Gen Intern Med. 1995;10:537-541.

24. McLaughlin GH. SMOG grading: A new readability formula. J Reading. 1969;12(8):639-646.

25. Kincaid JP, Fishburne RP, Rogers RL, Chissom BS. Derivation of new readability formula for Navy enlisted personnel. Millington, TN: Navy Research Branch; 1975.

26. Garbers S, Uribelarrea M, Foti H, Jones Jessop D, Chiasson M. Barriers to breast cancer screening for low-income Mexican and Dominican women in New York City. J Urban Health. 2003;80:81-91.

27. Schwartz LM, Woloshin S, Fowler FJ, Welch HG. Enthusiasm for cancer screening in the United States. JAMA. 2004;291:71-78.

28. Collins KS, Hughes D, Doty M, Ives B, Edwards J, Tenney K. Diverse Communities, Common Concerns: Assessing Health Care Quality for Minority Americans: Commonwealth Fund; March 2002. Accessed on January 15, 2009. Available from http://www.cmwf.org.

29. Marín G, Sabogal F, VanOss Marín B, Otero-Sabogal F, Pérez-Stable EJ. Development of a short acculturation scale for Hispanics. Hispanic J Behav Sci. 1987;9:183-205.

30. Nurss JR, Baker DW, Davis TC, Parker RM, Williams MV. Difficulties in functional health literacy screening in Spanish-speaking adults. J Reading. 1995;38(8):632-637.
31. Nurss JR, Parker RM, Williams MV, Baker DW. TOFHLA: Test of Functional Health Literacy in Adults. Snow Camp, NC: Peppercorn Press; 1995

32. Centers for Disease Control and Prevention (CDC). Cervical Cancer Screening. Accessed on January 29, 2009. Available from http://www. cdc.gov/cancer/cervical/basic_info/screening/.

33. Yabroff KR, Washington KS, Leader A, Neilson E, Mandelblatt J. Is the promise of cancer-screening programs being compromised? Quality of follow-up care after abnormal screening results. Med Care Res Rev. 2003;60:294-331.

34. Lillquist PP. Can case management be used to facilitate diagnostic testing in publicly funded breast cancer screening programs? Soc Work Health Care. 2004;40(2):55-71.

35. Vourlekis B, Ell K, Padgett D. Evidence-based assessment in case management to improve abnormal cancer screen follow-up. Health Soc Work. 2005;30(2):98-106.

36. Bastani R, Yabroff KR, Myers RE, Glenn B. Interventions to improve follow-up of abnormal findings in cancer screening. Cancer. 2004;101 (5 Suppl):1188-1200.

37. Gregory-Mercado KY, Will J, Starcher ET, et al. A combined approach to women's health is associated with a greater likelihood of repeat mammography in a population of financially disadvantaged women. Prev Chronic Dis. 2007;4(4):A89. 
